\title{
Utilização de imagens orbitais de alta resolução em superfícies com níveis distintos de impermeabilização do solo urbano: caso Irati-PR
}

\section{Use of high resolution images of orbital surface of waterproofing with different levels of urban land: case Irati-PR}

\author{
Bruno Cezar Gardens Lechiu; ; Paulo Costa de Oliveira Filho²; Jeanette Beber de \\ Sousa $^{3}$
}

\section{Resumo}

O objetivo desta pesquisa foi diagnosticar o uso e ocupação do solo urbano de uma área central de 0,23 $\mathrm{km}^{2}$ (15 quadras) do município de Irati, PR, voltado a diferentes níveis de impermeabilização, a partir de imagens orbitais do satélite Quickbird com resolução espacial de $0,60 \mathrm{~m}$, pelo método de interpretação e vetorização sobre tela seguido de classificação. A área ocupada pelas classes que representaram o nível mais impermeável foi de $33.218 \%$ enquanto que a área ocupada pelas classes que representaram o nível menos impermeável foi de $22.488 \%$ do total da área de estudo. Os resultados demonstram que a área de estudo encontra-se bastante impermeabilizada.

Palavras-chave: Sensoriamento remoto. Imagens quickbird. Vetorização sobre tela. Impermeabilização do solo urbano. Irati-PR.

\begin{abstract}
The objective of this research was to present a detailed diagnosis for use and occupation of urban land aimed at different levels of sealing, in a downtownIrati area of 14 blocks, totaling $0.23 \mathrm{~km}^{2}$, from the Quickbird satellite images with spatial resolution of $0.60 \mathrm{~m}$, by the method of interpretation and vectorization on the screen followed by classification. The area occupied by the classes that represent the highest level of waterproof is $33,218 \%$ of the total study area, since the area occupied by classes representing less impermeable level is $22,488 \%$ of the same area. The results show that the study area is well sealed.
\end{abstract}

Keywords: Remote sensing. Quickbird images. Vectorization on canvas. Impervious urban land. Irati-PR.

\section{Introdução}

Devido ao processo de ocupação urbana no Brasil, Tucci (1997) afirma que o aumento na frequência das inundações é consequência da impermeabilização e aumento do escoamento superficial na medida em que a cidade se urbaniza. Até mesmo em cidades de

\footnotetext{
Engenheiro Ambiental, Universidade Estadual do Centro-Oeste; bruno_ss75@hotmail.com

${ }^{2}$ Docente do Departamento de Engenharia Ambiental, Universidade Estadual do Centro-Oeste - DENAM/IUNICENTRO; paulocostafh@gmail.com

${ }^{3}$ Docente do Departamento de Engenharia Ambiental da Universidade Estadual do Centro-Oeste - DENAM/IUNICENTRO; jeanettebeber@yahoo.com.br
} 
pequeno e médio porte vem ocorrendo a substituição de áreas verdes e permeáveis por estruturas urbanas com diferentes graus de impermeabilização. Em alguns casos, este processo é em parte compensado pela aplicação de estruturas capazes de amenizar o impacto causado ao escoamento superficial natural, porém, muitas vezes esta preocupação não é levada em consideração e os materiais aplicados em algumas obras são, simplesmente, os menos onerosos.

Quando se substitui a rede de drenagem natural por estruturas artificiais, ocorre aumento na totalidade de áreas impermeáveis provocando o subsequente aumento na velocidade de escoamento das águas, o que é determinado pelo coeficiente de escoamento superficial. Em eventos chuvosos, este coeficiente representa a quantidade de água escoada pela bacia hidrográfica variando de acordo com fatores como a intensidade da chuva, sua distribuição espacial e temporal, condição de umidade e retenção do solo. Conforme Tucci e Marques (2001), o coeficiente de escoamento deve variar com a magnitude da precipitação, já que na medida em que a precipitação aumenta, as perdas iniciais e a capacidade de infiltração do solo são atendidas. Desta forma o escoamento superficial aumenta resultando num maior coeficiente de escoamento.

Baptista, Nascimento e Barraud (2005) aponta que a rápida evacuação das águas superficiais das áreas urbanas por meio de estruturas subterrâneas artificiais por gravidade, facilita a circulação viária e o desenvolvimento urbano, além de prevenir a disseminação de doenças de veiculação hídrica.

O objetivo da rede de microdrenagem urbana é transferir para a rede de macrodrenagem a água captada por todas as edificações e estruturas urbanas que impermeabilizaram o solo com o desenvolvimento da cidade de maneira rápida e eficiente.

Campana e Tucci (1994) comentam que a problemática da drenagem urbana na maioria das cidades brasileiras é consequência do aumento do pico de escoamento além de outros impactos mencionados. Já Tucci e Marques (2001) afirmam que, na medida em que a cidade se urbaniza pode ocorrer o aumento das vazões máximas, aumento na produção de sedimentos e consequente deterioração da qualidade da água.

Para o desenvolvimento urbano uma das etapas mais utilizadas antes da construção de uma edificação é a terraplanagem, a qual movimenta grande quantidade de terra, sendo esta transferida para diferentes pontos da bacia, sob a ação do vento, que movimenta as partículas para as ruas e calçadas e também das chuvas que carregam estas partículas para jusante. Com o aumento da taxa de escoamento superficial, mais partículas de terra são carregadas, ocasionando entupimento da rede de microdrenagem pela deposição de sedimentos.

Feltran-Filho, Lima e Rosa (1989) comentam que a forma como o solo é utilizado pelo homem pode provocar danos ao meio ambiente, sendo que alguns exemplos de seu mau uso são a erosão intensa e o assoreamento de reservatórios, lagos e rios, que contribuem significativamente para a inundação das áreas urbanas próximas aos mesmos.

A falta de planejamento na ocupação dos espaços urbanos, devido ao aumento da taxa populacional e do total de áreas impermeáveis, tem alterado significativamente os parâmetros que dizem respeito à impermeabilização de bacias hidrográficas urbanas. Araújo, Tucci e Goldemfum (2000) afirmam que as ações públicas para as soluções desse problema no Brasil estão voltadas, na maioria das vezes, somente para as medidas estruturais, que simplesmente transferem a inundação de um ponto para outro a jusante na bacia, sem que se avaliem os reais benefícios da obra.

A grande maioria das cidades brasileiras ainda possuem os sistemas clássicos de microdrenagem, que são constituídos por sarjetas, bocas de lobo e condutos subterrâneos que encaminham a água de escoamento para a rede de macrodrenagem. De acordo com Baptista e Nascimento (1996) apud 
Baptista, Nascimento e Barraud (2005) ocorreu uma intensa urbanização na segunda metade do século XX e com isso evidenciaram-se os limites das soluções clássicas de drenagem urbana e sua eficiência:

Ao retirar das áreas urbanizadas as águas de drenagem pluvial o mais rapidamente possível, transfere-se para a jusante os problemas de inundação. Nesse sentido, novas áreas urbanizadas têm tendência a provocar inundações mais frequentes em áreas de urbanização mais antigas. Como resultado, novas obras de drenagem deverão ser construídas a jusante, tais como aumento da seção transversal de canais naturais, substituição de condutos antigos por novos de maior diâmetro. Estas obras são, em geral, onerosas e seu custo deve ser suportado por toda a comunidade. Pág. 26

Todos estes fatores, apesar de alguns oferecerem certos benefícios, ocasionam no aumento das áreas impermeabilizadas, interferindo na velocidade de escoamento das águas das chuvas, aumentando a vazão e acarretando no acúmulo da carga hidráulica em certos pontos da rede coletora, isto resulta no aumento da magnitude das enchentes em áreas mais baixas da bacia ocasionando em prejuízos não somente ao poder público, mas também para a população em geral.

As áreas atingidas por enchentes, muitas vezes são ocupadas por famílias de baixa renda, com habitações irregulares ou por construções antigas que não sofreram, por exemplo, o efeito da Resolução CONAMA n ${ }^{\circ} 302$, de 20 de março de 2002 que determina em seu artigo $3^{\circ}$ que a Área de Preservação Permanente no entorno dos reservatórios artificiais deve ser de trinta metros para os reservatórios artificiais situados em áreas urbanas (COSELHO NACIONAL DO MEIO AMBIENTE, 2002). Assim, habitantes dessas áreas são mais vulneráveis a enchentes e possibilidade de contaminação devido ao contato com a água de lavagem urbana, por qualquer poluente de origem desconhecida, ou por doenças de veiculação hídrica. Pelo fato destas áreas ribeirinhas serem, na maioria das vezes, espaços urbanos pertencentes ao poder público, os órgãos governamentais muitas vezes conseguem transferir estes habitantes irregulares para outras áreas fora de risco, porém, sempre existe a possibilidade de uma nova invasão.

Há também problemas relacionados aos lotes em centros urbanos e arredores, que não respeitam o percentual mínimo de área não construída do terreno, ou seja, de área permeável, o que é previsto em Lei Federal e complementado ou não por legislação municipal. No caso do município de Irati, "a Lei Municipal n”. 2163 de 2004, que dispõe sobre o código de arquitetura, obras e edificações de Irati, define, em seu artigo 13, parágrafo único, a consulta prévia à legislação de uso e ocupação do solo e leis ambientais, antes da aprovação de projetos de edificações na cidade" (VENÂNCIO, et al., 2010).

Para que todo este acúmulo de água ocasionado pela urbanização não seja escoado para estas áreas mais baixas em períodos chuvosos, o controle mais eficiente deste problema é diretamente na própria fonte, ou seja, na microdrenagem urbana. Podem ser utilizadas técnicas capazes de controlar, ou ao menos amenizar o problema da impermeabilização do solo urbano, principalmente nas áreas centrais das cidades.

Baptista, Nascimento e Barraud (2005) propõe algumas técnicas compensatórias de caráter nãoestrutural, entre elas: racionalização do uso do solo urbano, educação ambiental, tratamento de fundo de vale e observância à legislação em si. Os mesmos autores ainda citam exemplos de técnicas de caráter estrutural, tais como: bacias de detenção, retenção, infiltração, obras lineares como trincheiras, valas e valetas, pavimentos permeáveis ou tipo reservatório, obras pontuais como poços, telhados armazenadores, entre outras.

A aplicação de algumas destas técnicas pode resolver, ou ao menos amenizar a problemática do aumento da taxa de escoamento superficial natural causada pela interferência da urbanização. Existe uma boa aplicabilidade das técnicas compensatórias estruturais nos centros urbanos, sendo que as lineares e as pontuais podem ser mais adequadas para esta situação, já que as bacias de detenção, por 
exemplo, abrangem uma área muito grande não se adequando à maioria dos centros urbanos.

Observando todos estes problemas, estudos detalhados de uso e ocupação do solo urbano com a utilização de imagens obtidas por fotografias aéreas, sensores orbitais e sub-orbitais tem sido conduzidos para que se realize uma abordagem mais eficiente e ampla destas questões. Os avanços do sensoriamento remoto nas resoluções espectrais e principalmente espaciais vêm tornando rotina o uso de imagens de alta resolução de satélites como o QuickBird e GeoEyeem a estudos urbanos. Estas imagens oferecem condições para a obtenção de informações diferenciadas para a identificação de elementos da composição urbana, como telhados, ruas, calçadas, gramados, entre outros. Entretanto, a escolha da imagem e a metodologia de trabalho devem ocorrer de acordo com os objetivos a serem alcançados e das necessidades para a identificação de objetos de diferentes dimensões. Para estudos detalhados do tecido urbano, há necessidade da utilização de imagens de alta resolução espacial, como as fornecidas pelo sensor do satélite QuickBird II, com pancromática de $0,61 \mathrm{~m}$.

Amaral, Ferreira Junior e Henriques (2007) identificaram ruas, calçadas, lagoas e áreas permeáveis e impermeáveis dentro de lotes utilizando fotografias aéreas verticais com escala aproximada de 1:5.000 no estudo de uso e ocupação do solo em uma bacia hidrográfica urbana. Leukert (2005) identificou áreas verdes, áreas verdes urbanas e áreas impermeáveis utilizando fotografias aéreas digitais na escala 1:5.000 na área de estudo. Pilz e Strobl (2005) identificaram telhados, terrenos impermeabilizados e não-impermeabilizados utilizando ortofotografias aéreas digitais na escala 1:1.000 no estudo das superfícies impermeabilizadas.

Vaeza et al. (2008) também utilizaram imagens do satélite Quickbird em estudo de impermeabilização do solo em bacia hidrográfica urbana no município de Irati, PR porém, definiram classes mais gerais, tais como ruas e calçadas, áreas permeáveis dentro de quadras e áreas impermeáveis dentro de quadras.

A cidade de Irati, Paraná, vem passando por profundas modificações em sua estrutura urbana. Entre as várias mudanças, tem sido muito discutida a substituição de paralelepípedos por asfalto, superfície bem menos permeável. A impermeabilização do solo urbano, de uma forma geral, torna importante estudos desta natureza.

O presente trabalho tem como objetivo apresentar um diagnóstico detalhado de uso e ocupação do solo urbano em uma área central de Irati, Paraná, a partir de imagens orbitais de alta resolução espacial e classificar os diferentes tipos de superfície em relação aos níveis de impermeabilização.

\section{Material e Métodos}

A área de estudo corresponde a uma área urbana, formada somente por 15 quadras, totalizando $0,23 \mathrm{~km}^{2}$ localizada no centro do município de Irati, Paraná, no fuso 22, hemisfério sul, entre as coordenadas geográficas Long 50³9' Oeste, Lat $25^{\circ} 28^{\prime}$ Sul e Long $50^{\circ} 38^{\prime}$ Oeste, Lat $25^{\circ} 27^{\prime}$ Sul, representada na Figura1.

Figura 1 - Localização da área do estudo.

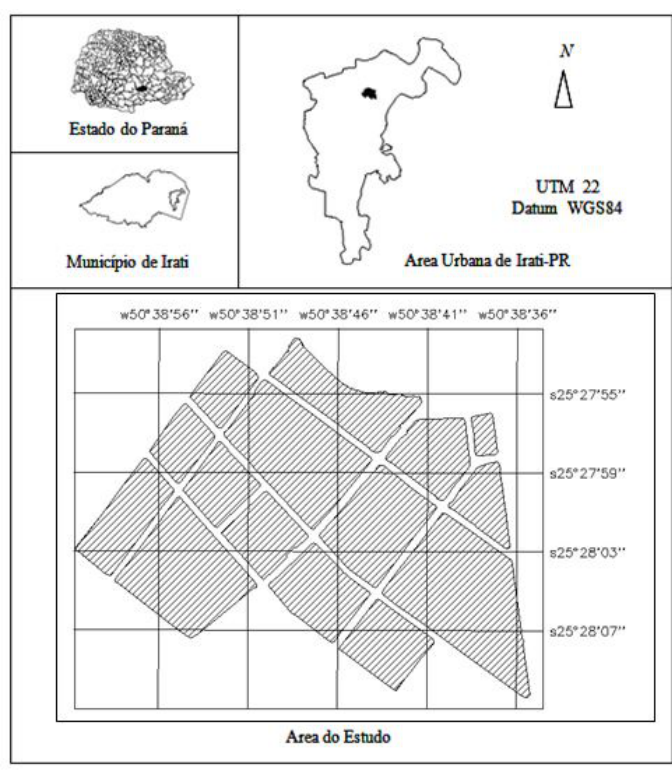

Fonte: os autores 
Para o estudo, foi utilizado um recorte do quadro urbano de um segmento de ortoimagens multiespectrais fusionadas com resolução espacial de $61 \mathrm{~cm}$, do sensor QuickBird a bordo do satélite QuickBird II, do ano de 2008. Esta imagem foi obtida junto ao Departamento de Planejamento da Prefeitura Municipal de Irati.

O software utilizado para os trabalhos de classificação foi o SPRING versão 5.0.6/INPE. Primeiramente foi efetuado o recorte da imagem no quadro urbano central, através de uma máscara vetorial.

A primeira etapa do trabalho foi realizada através do módulo de vetorização do aplicativo SPRING, utilizando as ferramentas de desenho para o delineamento e edição gráfica de fechamento ou topologia dos polígonos definidos pelo intérprete. A seguir, no modelo de dados do programa, foram criadas as classes definidas.

Os trabalhos de interpretação e classificação foram realizados considerando classes distintas de uso e ocupação do solo urbano direcionando à classificação para a relevância de níveis de impermeabilização. Foram definidas as seguintes classes: telhado com telhas de cerâmica, telhado com telhas de cimento-amianto, telhados metálicos, telhado com telhas de concreto ou laje, coberturas de lona (toldo), ruas, estacionamentos e calçadas asfaltadas, ruas pavimentadas com pedras (macacos), estacionamentos e calçadas concretadas, estacionamento recoberto com pedra brita ou cascalho, calçadas de petit pavê, calçadas de lousa, calçadas de blocos intertravados (paver), espaços verdes, cobertura arbórea, áreas descobertas. Cada elemento da composição urbana da área de estudo foi identificado e demarcado como um polígono fechado sem sobreposição de linhas, utilizando a topologia de vizinhança em ambiente de sistema de informações geográficas de modo a permitir uma maior precisão no cálculo das áreas. Após o trabalho de interpretação visual das imagens orbitais seguido da vetorização sobre tela, foi realizada a associação dos polígonos às classes pré-definidas no ambiente de sistema de informações geográficas do SPRING, resultando em uma classificação manual.

Para auxiliar a interpretação na identificação de cada classe, foram utilizadas fotografias inclinadas de pequeno formato colorido normal obtidas em março de 2011, do topo de um edifício de cerca de 30 metros de altura localizado no centro da área de estudo. Como a imagem do sensor Quickbird utilizada no estudo era do ano de 2008, foi importante também a visualização in loco, pois algumas áreas sofreram alterações no período de três anos, ou sofreram o efeito de sombreamento por algumas edificações mais altas, no momento da obtenção das imagens.

Também foram obtidas fotos in loco, com uma câmera fotográfica digital marca Sony, modelo DSC-W320, com lentes de $26 \mathrm{~mm}$ e capacidade de resolução de 14 megapixels.

O Tabela apresenta as 15 classes definidas nesse estudo, suas descrições, segmentos da imagem QuickBird e fotografias de campo respectivamente.

Tabela 1 - Classes de uso e ocupação do solo urbano

\begin{tabular}{ccc} 
Classe Descrição & Segmento & Fotografia \\
\hline & de Imagem & "in loco" (2011) \\
& QUICKBIRD \\
& $(2008)$ \\
\hline
\end{tabular}

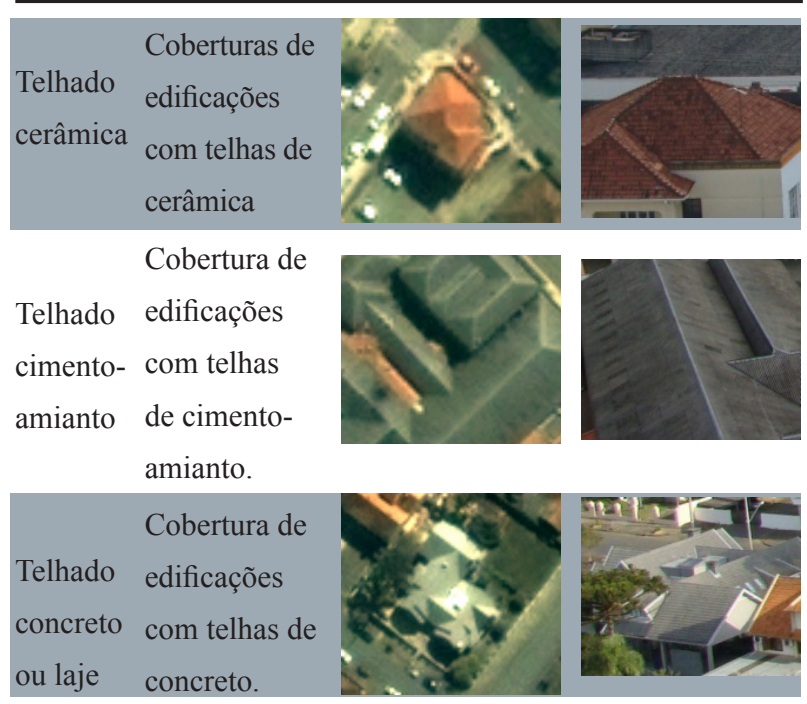




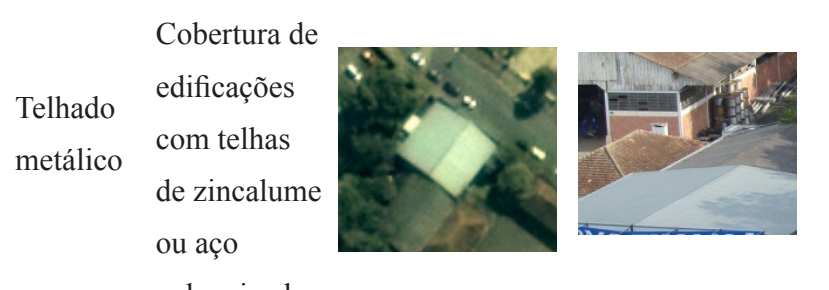

galvanizado.
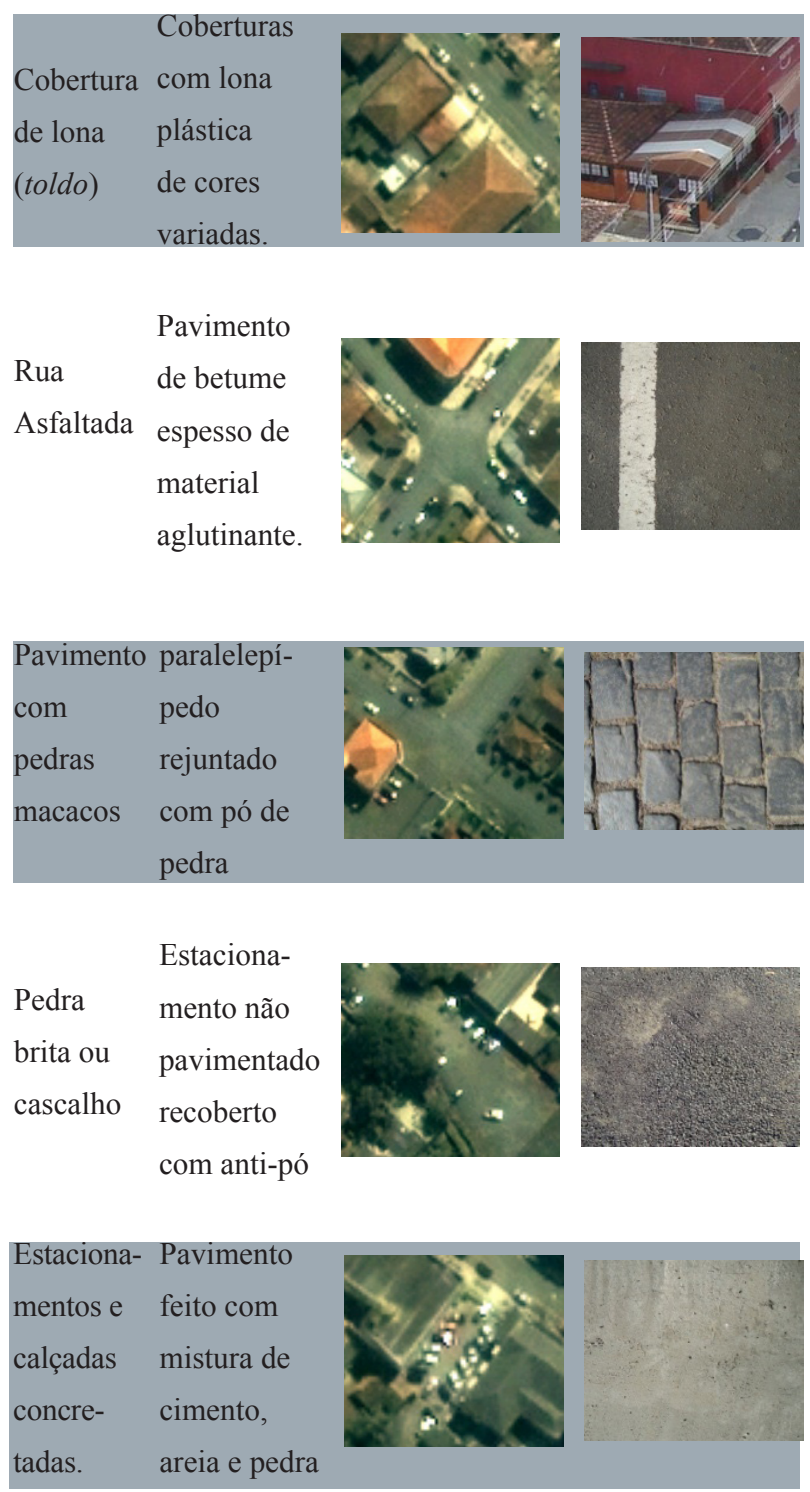
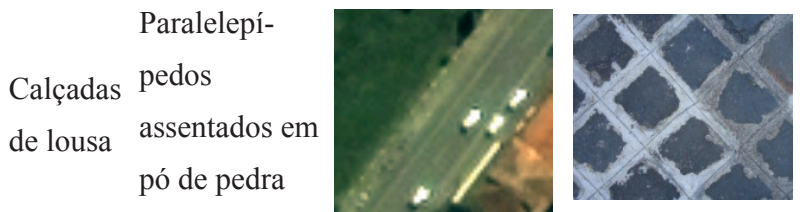

ou areia e

rejuntadas

com cimento

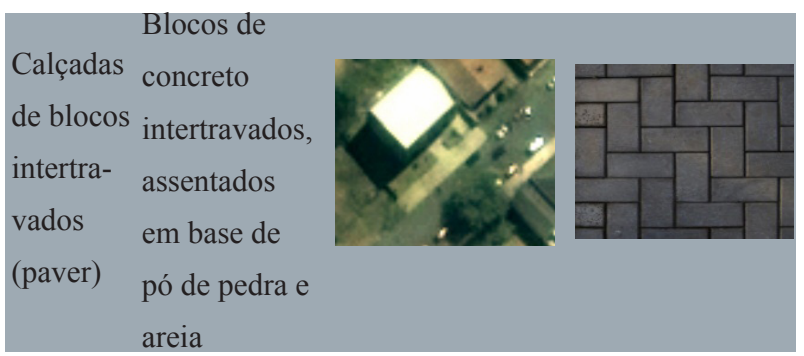

\section{Calçadas}

Calçadas pavimentadas

de petit com pedras

pavê. irregulares

assentadas em
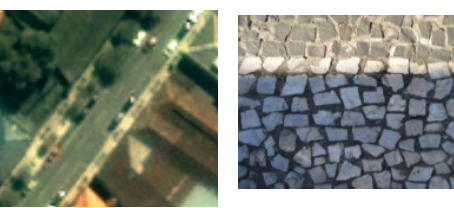

pó de pedra

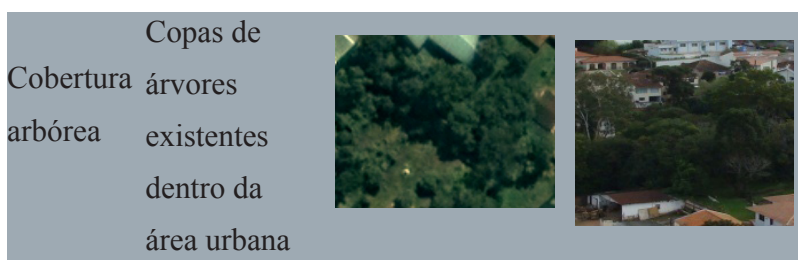

$$
\begin{array}{ll}
\text { Espaços } & \text { Áreas de } \\
\text { verdes } & \text { vegetação } \\
& \text { rasteira }
\end{array}
$$
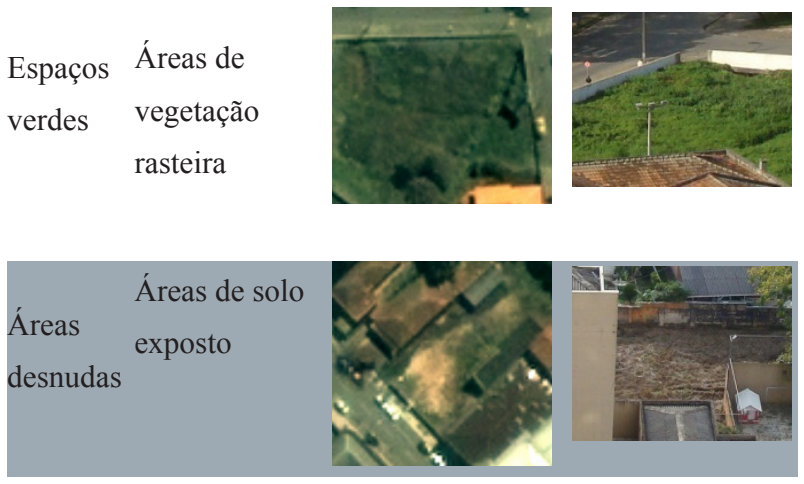

Fonte: os autores 
Após os trabalhos de interpretação e classificação, foi utilizado o software SCARTA versão 5.0.6/INPE, no qual foram efetuados os trabalhos de edição das cartas e elaborados dois resultados espaciais com suas respectivas legendas, um para mostrar a distribuição de cada classe na área de estudo e outro para representar o nível de impermeabilização do solo urbano na mesma área.

Para determinar o nível de impermeabilização das classes, baseou-se em pesquisas dos autores Araújo, Tucci e Goldemfum (2000) e Villela e Mattos (1980) os quais estimaram, através de experimentos, o coeficiente de escoamento superficial representado pela letra c. Este coeficiente é calculado pela razão entre as alturas efetiva e precipitada e necessita que alguns parâmetros sejam levados em conta, como o tipo e permeabilidade do solo, umidade antecedente e as características da superfície estudada.

Araújo, Tucci e Goldemfum (2000) realizou um experimento determinando o coeficiente de escoamento superficial de alguns pavimentos, entre eles estavam: solo compactado; pavimentos de granito; blocos de concreto; concreto; blocos vazados; e, concreto poroso; todos representados na Figura 2.

Figura 2 - Pavimentos utilizados no estudo: (a) solo compactado; (b) pavimento de granito; (c) blocos de concreto; (d) concreto; (e) blocos vazados; (f) concreto poroso

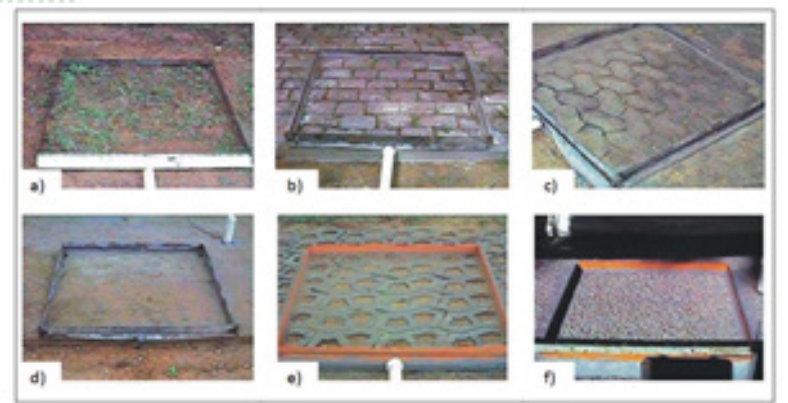

Fonte: Araújo, Tucci e Goldemfum (2000)
O estudo procedeu utilizando um simulador de precipitações com intensidades variáveis e vazão constante a uma altura de $4 \mathrm{~m}$, sobre cada uma das parcelas alvo de $1 \mathrm{~m}^{2}$. Os resultados obtidos por Araújo, Tucci e Goldemfum (2000) estão apresentados na Tabela 2. Podemos observar uma nítida redução dos valores do coeficiente de escoamento superficial quando se utiliza pavimentos mais permeáveis.

Tabela 2 - Resultados obtidos nas diferentes superfícies

$\overline{\text { Revestimento superficial Coeficiente de escoamento }}$ superficial

\begin{tabular}{ll}
\hline Concreto & 0.95 \\
Blocos de concreto & 0.78 \\
Solo compactado & 0.66 \\
Pavimento de granito & 0.60 \\
Blocos vazados & 0.03 \\
Concreto poroso & 0.005 \\
\hline
\end{tabular}

Fonte: Araújo, Tucci e Goldemfum (2000).

Todos os estudos em meio urbano envolvendo problemas com precipitações excessivas, que acabam ocasionando em problemas com enchentes, utilizam-se de valores muitas vezes obtidos em experimentos bastante simples, mas que podem resolver problemas de grandes magnitudes.

A Tabela 3 apresenta os resultados obtidos por Villela e Mattos (1980) sobre o coeficiente de escoamento superficial de algumas superfícies encontradas em uma bacia hidrográfica urbana, entre elas: telhados, asfalto, paralelepípedos, estradas mecanizadas, superfícies não-revestidas, solo na natureza, entre outros. 
Tabela 3 - Valores do coeficiente de escoamento superficial encontrados em algumas superfícies.

Revestimento superficial Coeficiente de escoamento superficial

Telhados perfeitos sem fuga

0.70 a 0.95

Superfícies asfaltadas em bom estado

0.85 a 0.90

Pavimentação de paralelepípedos,

0.70 a 0.85

ladrilhos ou blocos de madeira

com juntas bem tomadas

Para superfícies anteriores sem as

juntas tomadas

Pavimentação de blocos inferiores sem as juntas tomadas

Estradas mecanizadas

Estradas e passeios de pedregulho

0.15 a 0.30

Superfícies não-revestidas, pátios

0.10 a 0.30

de estradas de ferro e terrenos descampados, parques, jardins, dependendo da declividade

Do solo na natureza e do subsolo 0.01 a 0.20

Fonte: Vilella e Mattos (1980).
Pressupondo que, quanto maior o valor do escoamento superficial, menos permeável é o pavimento, e, tomando como base os diferentes valores do coeficiente de escoamento superficial obtidos nas Tabelas 2 e 3 e nos estudos de Araújo, Tucci e Goldemfum (2000) e Vilella e Mattos (1980), elaborou-se um gradiente dos níveis de impermeabilização ordenando o grau de impermeabilidade para diferenciar as classes encontradas na área de estudo.

\section{Resultados e Discussão}

A Figura 3 exibe o resultado espacial dos trabalhos de interpretação e classificação de uso e ocupação do solo urbano na área do estudo. Cada uma das classes citadas no Quadro1 foi associada a uma cor correspondente à sua classe de interpretação.

A classificação permitiu a diferenciação dos mais variados elementos da composição neste quadro urbano. Para representar cada classe foram selecionadas cores semelhantes com as que podem ser visualizadas na imagem. Telhados de cerâmica

Figura 3 - Representação espacial da classificação de uso do solo urbano da área de estudo.
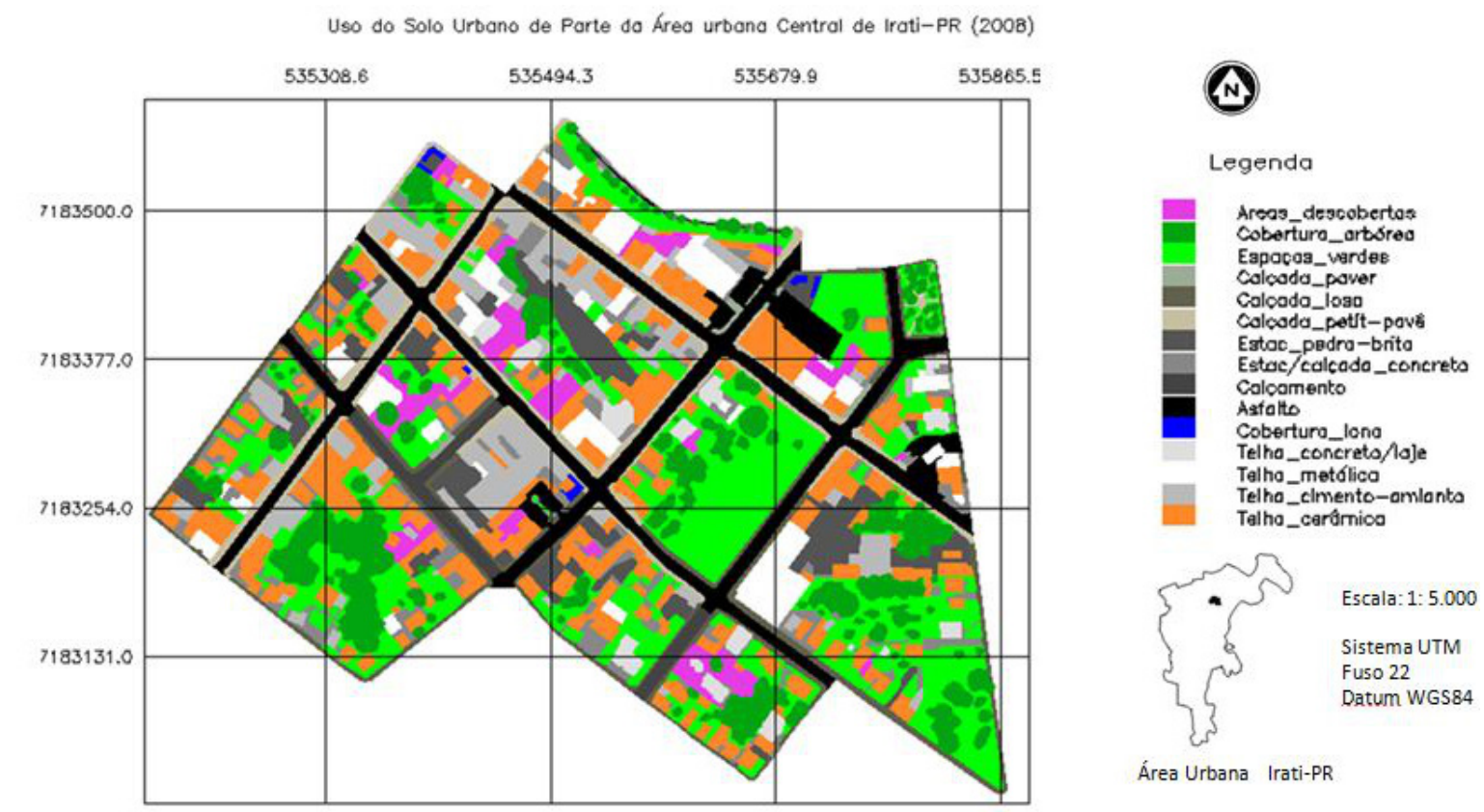

Fonte: Os autores 
foram associados a um único tom de laranja, pois mesmo variando entre laranja bem claro (telhados novos) e laranja mais escuro (telhados velhos), é de fácil identificação na imagem. Telhados de cimentoamianto e telhados com telhas de concreto ou laje receberam uma pequena variação no tom de cinza utilizado, pois um dos objetivos do trabalho foi diferenciar as classes e pela observação da imagem esta diferenciação foi possível, sendo que realmente existe uma pequena variação de nuance de cor entre elas, porém, o que facilitou a identificação foi o tamanho do telhado, pois telhas de cimento-amianto são mais utilizadas em construções comerciais. Telhados metálicos foram associados à coloração branca pelo fato de refletirem muito mais energia e aparecerem quase que nesta mesma coloração na composição colorida. Ruas asfaltadas e calçamentos aparecem na mesma tonalidade de cinza escuro na imagem, e para a diferenciação das mesmas foi necessária a visualização in loco, e a representação na imagem foi diferenciada pela cor preta para o asfalto e cinza escuro para o calçamento. Para a delimitação das calçadas públicas, foram utilizados os carros estacionados como base para diferenciar principalmente a calçada de lousa do calçamento e do asfalto, pois possuem praticamente a mesma coloração na imagem. Na Figura 2, calçadas de lousa aparecem em uma tonalidade de cinza um pouco mais clara do que representa o calçamento, e as calçadas de petit pavê são representadas em um tom bem mais claro. Calçadas de concreto foram uniformemente representadas por um tom de cinza, não levando em conta a grande variação de cores que podem apresentar, pois isto se deve ao tipo de material de cobertura, como lajotas de colorações variáveis. Estacionamentos de pedra brita foram demarcados como grandes áreas cinza dentro de lotes, estes são de fácil percepção na imagem. Áreas verdes foram representadas por verde claro e coberturas arbóreas por verde escuro, porém na imagem o melhor parâmetro para diferenciá-las é o fato de coberturas arbóreas possuírem um formato relativamente circular fato esse associado à sombra que elas produzem. Áreas descobertas variam em alguns tons de marrom e pelo fato de representarem somente em uma classe, receberam uma coloração roxa para fácil percepção. Coberturas de lona podem possuir variadas colorações na imagem e para sua representação foram associadas à cor azul.

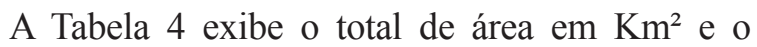
percentual de ocupação de cada classe de uso e ocupação do solo urbano.

Tabela 4 - Representação do total de áreas e suas respectivas percentagens.

\begin{tabular}{llcc}
\hline & Classe & Área $\left(\mathrm{Km}^{2}\right)$ & Ocupação (\%) \\
\hline 1 & Telhado com telhas de cerâmica & 0.042538 & 18.203 \\
2 & Telhado com telhas de cimento-amianto & 0.01667 & 7.135 \\
3 & Telhado com telhas de concreto ou laje & 0.004733 & 2.025 \\
4 & Telhados metálicos & 0.013124 & 5.616 \\
5 & Coberturas de lona (toldo) & 0.000559 & 0.239 \\
6 & Ruas, estacionamentos e calçadas asfaltadas & 0.028534 & 12.210 \\
7 & Ruas pavimentadas com pedras (macacos) & 0.004106 & 1.757 \\
8 & Estacionamento recoberto com pedra brita ou cascalho & 0.013574 & 5.809 \\
9 & Estacionamentos e calçadas concretadas & 0.012632 & 5.406 \\
10 & Calçadas de lousa & 0.010065 & 4.307 \\
11 & Calçadas de blocos intertravados (paver) & 0.000543 & 0.232 \\
& & & continua...
\end{tabular}


continuação...

\begin{tabular}{llcc}
\hline 12 & Calçadas de petit pavê & 0.010312 & 4.413 \\
13 & Cobertura arbórea & 0.023731 & 10.155 \\
14 & Espaços verdes & 0.045268 & 19.370 \\
15 & Áreas descobertas & 0.007287 & 3.118 \\
Área total dos Polígonos não classificados & 0.000012 & 0.005 \\
\hline & Área total & 0.233683 & 100 \\
\hline
\end{tabular}

Fonte: Os autores

De acordo com a Tabela 4 podemos observar que a classe de maior ocupação é a que representa os espaços verdes com $19.370 \%$ do total da área de estudo. Se esta for associada às áreas de cobertura arbórea, o total obtido é de $29.525 \%$ de áreas com maior capacidade permeável do solo.

O total de telhados e coberturas na área de estudo, detém $33.218 \%$, e este valor representa as classes com maior impermeabilidade, já que uma das funções de um telhado é a de desviar para as áreas de entorno toda a chuva que entra em contato com ele.

Se na área estudada existissem somente estas duas classes (espaços verdes/cobertura arbóreas; telhados/ coberturas) totalizando uma área de $0.146627 \mathrm{Km}^{2}$, teríamos $47.057 \%$ de áreas permeáveis contra $52.943 \%$ de áreas impermeáveis, ou seja, mais da metade da região estaria impermeabilizada. Porém, devemos levar em conta as outras classes, pois cada uma possui um valor distinto de infiltração. Os calçamentos, calçadas de petit pavê ou paver podem ser consideradas classes menos impermeáveis pelo fato de possuírem uma área relevante de juntas, estas facilitando a infiltração da água. Já as calçadas e estacionamentos de concreto, superfícies asfaltadas e calçadas de lousa, não possuem juntas, por outro lado, podem conter trincas, as quais possuem menor área de infiltração de água, sendo, portanto, consideradas como mais impermeáveis.
Tabela 5 - Níveis de impermeabilização das diferentes classes de uso e ocupação do solo urbano realizados para o presente estudo.

\begin{tabular}{|c|c|c|c|}
\hline & Classes & $\begin{array}{l}\text { Valor de } \\
\text { escoamento } \\
\text { superficial }\end{array}$ & $\begin{array}{l}\text { Gradiente de } \\
\text { Impermeabilização }\end{array}$ \\
\hline 1 & Telhados e Coberturas & 0.95 & \\
\hline 2 & $\begin{array}{l}\text { Estacionamentos e } \\
\text { calçadas concretadas }\end{array}$ & 0.95 & $\begin{array}{l}\mathrm{I} \\
\mathrm{M} \\
\mathrm{P}\end{array}$ \\
\hline 3 & Superfícies asfaltadas & 0.90 & $\begin{array}{l}\mathbf{E} \\
\mathbf{R}\end{array}$ \\
\hline 4 & Calçadas de lousa & 0.85 & $\begin{array}{l}\mathbf{M} \\
\mathbf{E}\end{array}$ \\
\hline 5 & Calçadas de paver & 0.78 & $\begin{array}{l}A \\
B\end{array}$ \\
\hline 0 & Calçadas de petit pavê & 0.70 & I \\
\hline 7 & Áreas descobertas & 0.66 & $\begin{array}{l}\text { L } \\
\text { I }\end{array}$ \\
\hline 8 & $\begin{array}{l}\text { Ruas pavimentadas } \\
\text { com pedras (macacos) }\end{array}$ & 0.60 & $\begin{array}{l}\mathbf{Z} \\
\mathrm{A} \\
\mathrm{C}\end{array}$ \\
\hline 9 & $\begin{array}{l}\text { Estacionamento } \\
\text { de pedras brita ou } \\
\text { cascalho }\end{array}$ & 0.30 & $\stackrel{\AA}{0}$ \\
\hline 10 & Espaços verdes & 0.20 & \\
\hline 11 & Cobertura arbórea & 0.01 & $\sqrt{ }$ \\
\hline
\end{tabular}

Fonte: Os autores 
Estas 11 classes de impermeabilidade foram definidas tomando como base a semelhança entre os materiais citados pro Araújo, Tucci e Goldemfum (2000) e por Villela e Mattos (1980). Os valores de coeficiente de escoamento superficial adotados foram os máximos apresentados nas Tabelas 2 e 3 e o quesito de determinação destes valores foi o comparativo entre a descrição dos autores das tabelas e a visualização in loco dessas classes na área de estudo.

Primeiramente, os valores de escoamento superficial considerados paras as classes de 1 e 2 são iguais, porém, telhados e coberturas são as classes mais impermeáveis por se tratarem de superfícies que não recebem infiltração de água; pavimentos concretados podem receber alguma infiltração através de alguma trinca ou falha em suas estruturas; calçadas de lousa foram consideradas como sendo pavimentos comjuntas bem tomadas; calçadas depetit pavê foram considerados como sendo pavimentos sem juntas tomadas; áreas descobertas foram comparadas ao solo compactado; ruas pavimentadas com pedras (macacos) foram comparadas com o pavimento de granito; estacionamentos de pedra brita ou cascalho foram associados a estradas e passeios de pedregulho; para os espaços verdes foi considerado a média de superfícies de parques e jardins coincidindo com o máximo valor do solo na natureza e por fim, cobertura arbórea, onde foi considerando o fato de que as árvores somadas no estudo foram somente de áreas dentro de lotes, onde geralmente são plantadas no meio de gramados ou áreas não calçadas. A estas foi associado o valor mínimo apresentado na Tabela 3 pelo fato de as folhas das árvores diminuírem a velocidade de impacto das gotas de chuva, diminuindo a velocidade de escoamento superficial facilitando assim, a infiltração no solo; o restante das classes pode ser localizado pela semelhança da descrição. A seguir, este gradiente de impermeabilidade foi representado espacialmente pelas classes da Tabela 4, desde as mais impermeáveis (cores quentes) até as menos impermeáveis (cores mais frias) e é apresentado na Figura 4.

Figura 4 - Representação da distribuição espacial das diferentes classes de impermeabilização do solo urbano na área estudada.

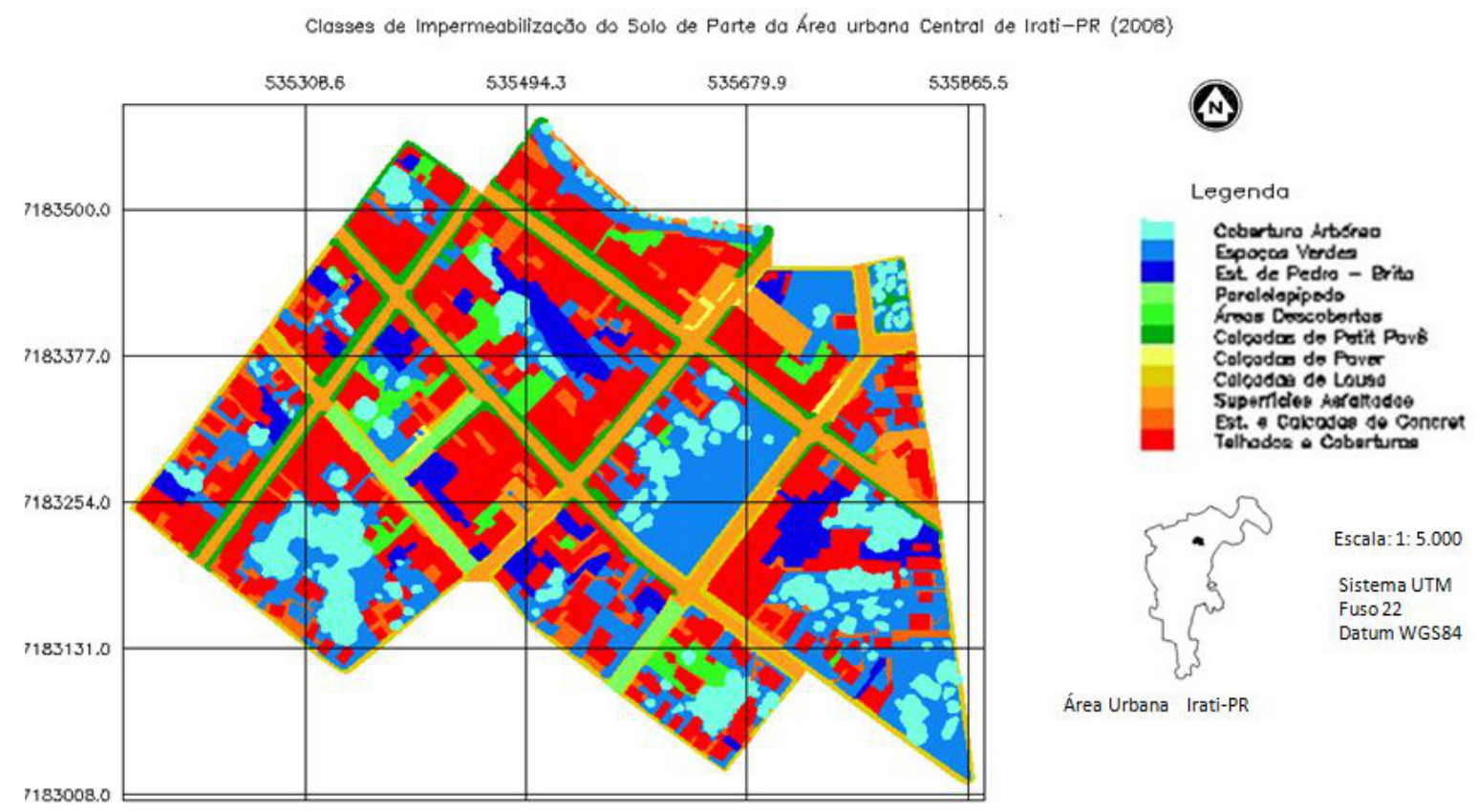

Fonte: Os autores 
$\mathrm{Na}$ tabela 5 são apresentados o total de área em $\mathrm{Km}^{2}$ e o percentual de ocupação de cada classe da Tabela 4, em seu nível distinto de impermeabilização. Observando os índices apresentados na Tabela 5, pode-se observar o grande percentual de ocupação da classe de telhados e coberturas, que possuem o maior grau de impermeabilidade, detendo um valor de $33.218 \%$ do total da área de estudo.

Associando-se as classes de nível 1, 2, 3 e 4 que possuem valores de coeficiente de escoamento superficial acima de 0.85 por possuírem juntas bem tomadas, poucas ou nenhuma trinca, o total de áreas praticamente impermeáveis detêm um índice de $55,141 \%$ da área total do estudo.

Tabela 5 - Representação do total de áreas impermeáveis e suas respectivas percentagens

\begin{tabular}{|c|c|c|c|}
\hline & Classe & $\begin{array}{l}\text { Área } \\
\left(\mathrm{Km}^{2}\right) \\
\end{array}$ & $\begin{array}{l}\text { Percentual de } \\
\text { ocupação (\%) }\end{array}$ \\
\hline 1 & Telhados e coberturas & 0.077628 & 33.218 \\
\hline 2 & $\begin{array}{l}\text { Estacionamentos e } \\
\text { calçadas de concreto }\end{array}$ & 0.012632 & 5.406 \\
\hline 3 & Superfícies asfaltadas & 0.028534 & 12.210 \\
\hline 4 & Calçadas de lousa & 0.010065 & 4.307 \\
\hline 5 & Calçadas de paver & 0.000543 & 0.232 \\
\hline 6 & Calçadas de petit pavê & 0.010312 & 4.413 \\
\hline 7 & Áreas descobertas & 0.007287 & 3.118 \\
\hline 8 & Ruas de paralelepípedo & 0.004106 & 1.757 \\
\hline 9 & $\begin{array}{l}\text { Estacionamento } \\
\text { de pedra brita }\end{array}$ & 0.013574 & 5.809 \\
\hline 10 & Espaços verdes & 0.045268 & 19.370 \\
\hline \multirow[t]{3}{*}{11} & Cobertura arbórea & 0.023731 & 10.155 \\
\hline & $\begin{array}{l}\text { Área total de Polígonos } \\
\text { não classificados }\end{array}$ & 0.000012 & 0.005 \\
\hline & Área total & 0.233683 & 100 \\
\hline
\end{tabular}

Fonte: Os autores

As classes com valores de coeficiente de escoamento superficial entre 0.60 e 0.78 , por não possuírem juntas tomadas e a área destas serem relativamente maiores comparadas com as das classes com valores mais elevados, foram consideradas parcialmente impermeáveis, detendo um valor de $9.520 \%$ do total da área de estudo.

Representando as áreas com menor valor de coeficiente de escoamento superficial, entre $0.01 \mathrm{e}$ 0.30, foram classificadas as áreas com vegetação, solos não compactados e consequentemente menos impermeáveis, detendo um valor de $35.334 \%$ do total da área de estudo.

Mesmo somando o total de áreas menos impermeáveis com as parcialmente impermeáveis o resultado é de $44.854 \%$ da área total, desta forma, esta região, ainda assim, pode ser considerada impermeabilizada, pois este valor não supera os $55.141 \%$ de áreas mais impermeáveis.

Para que este índice fosse reduzido, seria necessário um aumento significativo no total de áreas pavimentadas com materiais que possuem coeficientes de escoamento superficial entre 0.60 e 0.78 , já que é difícil implantar áreas verdes em um centro urbano já consolidado. A substituição de estacionamentos, calçadas de concreto e de lousa por paver ou petit pavê, reduziria esse índice para $45,428 \%$ de áreas mais impermeáveis, aumentando consequentemente as áreas menos e parcialmente impermeáveis para um total de 54,5675\%, amenizando um pouco este problema. Por outro lado, o custo para a implantação desta medida teria que ser suportado pelos cofres públicos, acarretando provavelmente um aumento da alíquota de impostos para a população.

A utilização de algumas técnicas compensatórias na drenagem urbana, substituindo alguns pavimentos mais impermeáveis por outros menos impermeáveis poderia amenizar um pouco estes resultados, porém isto acarretaria em custos para a sociedade. Tendo em vista que a cidade de Irati tende a crescer ainda mais com o passar dos anos, deve-se pensar em soluções a longo prazo para amenizar estes problemas, na realização de novas obras, substituindo, aos poucos, pavimentos impermeáveis por outros mais permeáveis, para que os custos sejam suportados pelos contribuintes. 


\section{Conclusões}

- O processo de interpretação e vetorização sobre tela, seguida de classificação utilizando imagens orbitais de altíssima resolução possibilitou identificar 15 classes de uso e ocupação do solo urbano na área do estudo;

- Os índices de áreas verdes e coberturas arbóreas somaram $29.525 \%$ do total da área estudada, não superando os índices obtidos de telhados e coberturas, que detiveram $33,218 \%$ da área total;

- Avaliando classes de diferentes níveis de impermeabilização, porém com coeficientes de escoamento superficial muito próximos, podese comprovar que a área em questão encontra-se bastante impermeabilizada, pois as três classes com nível de escoamento superficial mais elevado somam um total de $55.14 \%$ da área de estudo e as três classes com nível de escoamento superficial mais baixo somam apenas $35.34 \%$ da área.

\section{Referências}

AMARAL, R. F.; FERREIRA JUNIOR, A. V., HENRIQUES, A. P. M. Aplicações em estudos ambientais no Rio grande do Norte. In: DISPERATI, A. A.; AMARAL, R. F.; SCHULER, C. A. B. Fotografias aéreas de pequeno formato: aplicações ambientais. Guarapuava: UNICENTRO, 2007. p. 179-218.

ARAUJO, P. R.; TUCCI, C. E. M.; GOLDEMFUM, J. A. Avaliação da eficiência dos pavimentos permeáveis na redução do escoamento superficial. Revista Brasileira de Recursos Hidricos, Porto Alegre, v. 5, n. 3, p. 21-29, jul./ set. 2000.

BAPTISTA, M.; NASCIMENTO, N.; BARRAUD, S. Técnicas compensatórias em drenagem urbana. Porto Alegre: SAGRA, 2005. v. 1.

CAMPANA, N.; TUCCI, C. E. M. Estimativa de área impermeável de macrobacias urbanas. Caderno de Recursos Hídricos, v. 12, n. 2, p. 79-94, 1994.

COSELHO NACIONAL DO MEIO AMBIENTE. Resolução $N^{o}$ 302, de 20 de março de 2002. Dispõe sobre os parâmetros, definições e limites de Áreas de Preservação Permanente de reservatórios artificiais e o regime de uso do entorno. Disponível em: $<\mathrm{http} / / / \mathrm{www}$. mma.gov.br/port/conama/res/res02/res30202.html $>$.
Acesso em: 5 nov. 2011.

FELTRAN-FILHO, A. F.; LIMA S. C.; ROSA, R. Mapeamento do uso do solo no município de Uberlândia - MG, através de imagens TM/LANDSAT. Sociedade \& Natureza, Uberlândia, v. 1 p. 127-145, 1989.

LEUKERT, L. Utilização de dados de SIG para a obtenção de objetos. In: BLASCHKE, T.; KUK, H. Sensoriamento remoto e SIG avançados. São Paulo: Oficina de Textos, 2005. p. 145-152.

PILZ, H.; STROBL, J. Análise de impermeabilização com base em ortofotografias aéreas coloridas digitais através de processamento de imagens orientadas a objetos. In: KUX, H.; BLASCHKE, T. Sensoriamento remoto e SIG avançados. São Paulo: Oficina de Textos, 2005. p. 164-171.

TUCCI, C. E. M. Plano diretor de drenagem urbana: princípios e concepção. Revista Brasileira de Recursos Hídricos, Porto Alegre, v. 2, n. 2, p. 5-12, jul./dez. 1997.

TUCCI, C. E. M.; MARQUES, D. M. L. M. Avaliação e Controle da Drenagem Urbana. Porto Alegre: ABRH, 2001.

VAEZA, R. F.; OLIVEIRA-FILHO, P. C.; MAIA, A. G.; DISPERATI, A. A. Uso e ocupação do solo urbano em bacia hidrográfica Urbana a partir de imagens orbitais de alta resolução. Floresta e Ambiente, Rio de Janeiro, v. 17, n. 1, p. 23-29, jan./jun. 2010.

VILLELA, S. M.; MATTOS, A. Hidrologia aplicada. São Paulo: McGraw-Hill do Brasil, 1980. v. 2.

VENÂNCIO, D. L.; OLIVEIRA-FILHO, P.C.; DISPERATI, A.A. Uso do geoprocessamento em estudo ambiental na bacia hidrográfica do rio das Antas, Irati (Paraná). Revista Ambiência, Guarapuava, V. 6 N. 1 Jan./ Abr., 2010

Recebido em 21 Dezembro 2011-Received on December 21, 2011. Aceito em 10 Março, 2012 - Accepted on March 10, 2012. 
